\title{
Absorption Rates of Subcutaneously Injected Insulin in the Dog as Calculated from the Plasma Insulin Levels by Means of a Simple Mathematical Model
}

\author{
U. Fischer, E.-J. Freyse, E. Jutzi, W. Besch, M.Raschke, S. Höfer and G. Albrecht \\ Central Institute of Diabetes ‘Gerhardt Katsch', Karlsburg, GDR
}

\begin{abstract}
Summary. The appearance rate of insulin (calculated insulin secretion rate) in the circulating blood after subcutaneous injection was estimated in diabetic dogs from serial measurements of immunoreactive insulin concentrations using a simple mathematical model based on the insulin half-life and the distribution space. In the case of highly purified monocomponent porcine insulin, maximum concentrations occurred after $30-60 \mathrm{~min}$. The duration of insulin appearance was dosedependent and the rate of appearance could be described by a bi-exponential function. It was linearly dose-dependent but the effect on glycaemia showed saturation kinetics. The action
\end{abstract}

of the injected dose on the fasting glycaemia diminished when the appearance rate became $<0.3 \mathrm{mU} \cdot \mathrm{kg}^{-1} \cdot \mathrm{min}^{-1}$. Fractional dose recovery was between $70 \%$ and $90 \%$ and was not different between depot and regular insulin. Appearance kinetics were not significantly affected by the initial glycaemia. The model presented provides a means for quantitative characterization of different insulin preparations.

Key words: Dog, insulin therapy, mathematical model, soluble insulin, depot insulin, absorption. subcutaneous.
Until artificial B cells and transplantation are available for the routine long-term treatment of insulin-dependent diabetes, therapeutic research will concentrate mainly on improving the subcutaneous administration of insulin. One approach to this problem is to determine individual optimal insulin dose profiles by means of glucose-controlled insulin infusions and to transpose them into a pattern of separate subcutaneous injections of a variety of preparations [19]. On the other hand, continuous subcutaneous insulin infusions by means of open loop systems are becoming increasingly popular $[13,22,24]$.

For successful use, however, both methods require not only carefully recorded blood glucose curves [21] but also detailed knowledge regarding the kinetics of insulin absorption from the subcutaneous injection depot to the insulin distribution space $[1,12]$. A large number of detailed studies on the disappearance of insulin from its injection depot and how it can be influenced have been reported [2-6, 17, 18, 20, 23, 25]. Moreover Stevenson et al. [26] reported an approach to quantify the absorbed amount of subcutaneously injected insulin by matching the blood glucose response to a programmed intravenous insulin infusion. For practical purposes, a simple mathematical model based on the analysis of pe- ripheral insulin concentrations and estimation of the rate at which insulin appears in its distribution system seems suitable for obtaining more detailed information [10]. If an organism devoid of functioning B cells is taken as the experimental subject, the rate of insulin appearance can be calculated for any therapeutic dose.

The purpose of this study was to use a model to describe the kinetics of insulin appearance after subcutaneous administration of a variety of insulin preparations. The tests were performed on dogs with experimentally induced diabetes because with these animals an initial state free of endogenous insulin can be most easily reproduced for observation.

\section{Materials and Methods}

\section{Model}

The insulin concentration (IRI) in the peripheral blood plasma is determined by two factors: a continuous loss (binding to receptors, metabolism, excretion) and a possible supply (secretion or, in the diabetic state, injection or infusion). The present model represents the first of these two quantities by means of the plasma insulin half-life $\tau$. In normal subjects the change in plasma IRI during a given interval $\Delta t$ depends on the calculated insulin secretion rate (CISR), which compensates more or less for the insulin decline during $\Delta t$, and, in addi- 
Table 1. Basic characteristics of the eight experimental dogs

\begin{tabular}{lcl}
\hline Age [months] & 34 & \pm 5 \\
Duration of diabetes [months] & 9 & \pm 2 \\
Daily insulin dose [U/kg] & 1.4 & \pm 0.2 \\
Body weight $[\mathrm{kg}]$ & 23.8 & $\pm 1.7^{\mathrm{a}}$ \\
& 23.9 & $\pm 1.9^{\mathrm{b}}$ \\
Insulin half-life [min] & 2.9 & $\pm 0.2^{\mathrm{a}}$ \\
& 2.7 & $\pm 0.2^{\mathrm{b}}$ \\
Insulin space [ml $/ \mathrm{kg}]$ & 149 & $\pm 22^{\mathrm{a}}$ \\
& 141 & $\pm 22^{\mathrm{b}}$ \\
Fasting plasma IRI [nmol/l] & & \\
$\quad$ Experimental dogs & $0.062 \pm 0.009$ \\
Control dogs $(n=17)$ & $0.151 \pm 0.023^{\mathrm{c}}$ \\
\hline
\end{tabular}

Results expressed as mean \pm SEM

${ }^{a}$ at the beginning of the observation; ${ }^{b}$ at the end of the experimental period which was between 2 and 4 weeks in the individual dogs; ${ }^{c} p<0.01$ compared with the diabetic dogs. These animals were studied during the same period for other purposes

tion, accounts for any increase in concentration. According to Fischer et al. [9], this gives the equation

$\operatorname{CISR}_{\Delta \mathrm{t}}=\mathrm{F} \cdot \operatorname{IS}\left[\operatorname{IRI}_{\mathrm{t}+\Delta \mathrm{t}}-\operatorname{IRI}_{\mathrm{t}}\left(\mathrm{e}^{-\ln 2 \cdot \Delta \mathrm{t} / \tau}\right)\right]$

where $\mathrm{F}$ denotes a constant for the first pass hepatic insulin loss and IS is the distribution space which is regarded as a single compartment. Equation (1) also applies for the calculated insulin inflow rate (CIIR) into IS after post-hepatic administration (e.g. SC injection). In this case, $F$ equals 1.0 because there is obviously no first pass hepatic insulin loss before distribution of the peripherally administered dose. In addition, formula (1) has to be corrected for the difference between the continuity of the biological process of insulin distribution and degradation, and the calculation at discrete intervals. This correction depends both on $\tau$ and on $\Delta \mathrm{t}$ :

$\mathrm{CIIR}_{\Delta \mathrm{t}}=\operatorname{IS}\left[\mathrm{IRI}_{\mathrm{t}} \cdot \ln 2 \cdot \Delta \mathrm{t} / \tau+\Delta \operatorname{IRI}(1+\ln 2 \cdot \Delta \mathrm{t} / \tau)\right]$

$\Delta \mathrm{IRI}$ is the change in plasma insulin concentration during $\Delta \mathrm{t}$.

Repeated, closely spaced IRI measurements and knowledge of the values of $\tau$ and IS are necessary in order to calculate the insulin inflow rates by this method. These formulae are valid for calculation of CIIR from SC injection depots only if the animal's B cells are not functioning.

\section{Animals and Experiments}

The observations were made on eight Alsatian dogs of both sexes which had been rendered diabetic by subtotal pancreatectomy and intrasurgical streptozotocin application into the superior pancreaticoduodenal artery (Table 1). The diabetes was treated with three injections daily of highly purified monocomponent porcine insulin. Details of the experimental conditions have been described previously [10]. The plasma insulin concentrations $12-14 \mathrm{~h}$ after the last SC insulin injection were either below or near to the lower detection level. There was no response to IV or oral glucose. The half-life $\tau$ and distribution space IS of the exogenous insulin were determined from the least-squares linear fit of the log IRI curves after IV injection of highly purified monocomponent porcine insulin $50 \mathrm{mU} / \mathrm{kg}$ (measuring intervals $1 \mathrm{~min}$, maximum concentration $1.8-2.5 \mathrm{nmol} / \mathrm{l}$, Table 1 ). The animals were examined $14 \mathrm{~h}$ after their last meal and insulin injection. Blood was sampled from an upper leg vein through an indwelling cannula. Plasma glucose and IRI concentrations ( $\Delta \mathrm{t}=5$ or $10 \mathrm{~min}$ ) after SC injection of $0.16,0.24,0.40$ or $0.64 \mathrm{U} / \mathrm{kg}$ of different insulin preparations were measured for $6 \mathrm{~h}$ (soluble insulin) or up to $24 \mathrm{~h}$ (depot insulin preparations, but with analyses only twice an hour after $14 \mathrm{~h})$.

The insulin solutions injected were $\mathrm{pH}$-neutral commercial preparations $(40 \mathrm{IU} / \mathrm{ml})$ from different manufacturers. The insulin was taken from freshly opened ampoules and injected SC through shaved skin in the middle of the neck under sterile conditions by means of calibrated $0.5 \mathrm{ml}$ syringes and 26 gauge stainless steel cannulae (15 mm long). The following insulin preparations were used: (a) soluble insulin: highly purified monocomponent porcine insulin (Actrapid, Novo Industri, Copenhagen); (b) soluble insulin: single peak porcine insulin (SNC, VEB Berlin-Chemie, Berlin, GDR); (c) depot insulin formulation of a suspension of chromatographically purified, bovine insulin crystals $(75 \%)$ in a solution of highly purified monocomponent porcine insulin (25\%) (Rapitard, Novo); (d) depot insulin formulation: mixture of $50 \%$ amorphous and $50 \%$ crystalline bovine insulin (Berl L, Berlin-Chemie).

The individual animals were subjected to two to six tests in random distribution and random order, at intervals of 5 days to 2 weeks.

\section{Analyses and Evaluation}

The plasma glucose (Beckman Instruments, Fullerton, California, USA) and IRI concentrations (back-titration, alcohol precipitation) were measured [14]. The detection range of the radioimmunoassay was between 0.05 and $1.00 \mathrm{nmol} / 1(0.05 \mathrm{nmol} / 1=2 \mathrm{SD}$ range of the zero control value), and the day-to-day coefficients of variation were $6.1 \%$ at $0.7 \mathrm{nmol} / 1$ and $10.2 \%$ at $0.35 \mathrm{nmol} / 1$. There were identical calibration curves for bovine, porcine, and canine insulins, and $100 \%$ cross-reactivity at all concentrations.

The absence of anti-insulin antibodies was proved in all animals. This was done by testing for displacement of ${ }^{125} \mathrm{I}$-insulin by $170 \mathrm{nmol} / 1$ of unlabelled insulin from its binding on plasma proteins in comparison with a mixed canine normal serum (rapid semi-quantitative assay for high affinity antibodies). The insulin binding capacity was estimated by highly purified, biologically fully active mono- ${ }^{125} \mathbf{I}$ insulin at 7.0 and $0.07 \mathrm{nmol} / 1$ after the samples had been incubated with charcoal at $\mathrm{pH} 3.0$, titrated with $\mathrm{H}_{3} \mathrm{PO}_{4}(1 \mathrm{~mol} / 1)$, and subsequently neutralized using $\mathrm{NaOH}(1.0 \mathrm{~mol} / 1)$.

The insulin distribution time within the circulation was $1.20 \pm$ $0.20 \mathrm{~min}(n=10$, diabetic dogs) and $1.23 \pm 0.13 \min (n=22$, control animals) respectively as estimated from IV injection tests with $50 \mathrm{mU} / \mathrm{kg}$ highly purified monocomponent porcine insulin. Accordingly in the experiments reported on here the insulin inflow rates (CIIR) after SC injection were calculated at intervals of $1 \mathrm{~min}$ by means of formula (2), based upon the plasma IRI levels after the initial levels had been subtracted. For this the measured values were linearly interpolated at 1 -min intervals and the 5-point moving average was taken from these numbers. For curve plotting the mean CIIR over intervals of 10 or $30 \mathrm{~min}$ was taken (Figs. 1 and 3). Based upon the assumption that the plasma IRI increase after the SC injection is produced exclusively by the insulin absorbed from the injection site, the dose recovery was calculated. This is the CIIR sum over all $1 \mathrm{~min}$ intervals during the period for which $\left(\mathrm{IRI}_{\mathrm{t}}-\mathrm{IRI}_{0 \mathrm{~min}}\right)>0$, expressed as percentage of the dose administered. The mean \pm SEM of the measured and calculated data are given and statistical significance at the $1 \%$ significance level was proved using the t-test.

\section{Results}

The appearance of insulin from a depot of highly purified monocomponent porcine insulin (a) was already significant during the first 10 min-interval. Maximal appearance rates were reached after about $30 \mathrm{~min}$ (Fig. 1); their magnitude and duration depended on the dose. The maximum concentrations obtained were $0.37 \pm$ $0.08 \mathrm{nmol} / 1 \quad$ (dose: $0.16 \mathrm{IU} / \mathrm{kg}), \quad 0.61 \pm 0.04 \mathrm{nmol} / 1$ $(0.24 \mathrm{IU} / \mathrm{kg}), \quad 0.48 \pm 0.08 \mathrm{nmol} / 1 \quad(0.40 \mathrm{IU} / \mathrm{kg})$ and $0.82 \pm 0.22 \mathrm{nmol} / 1(0.64 \mathrm{IU} / \mathrm{kg})$. No appreciable quantities appeared after the fifth hour. In order of increasing doses, the recovery was $87 \pm 5 \%, 83 \pm 36 \%, 73 \pm 26 \%$ 

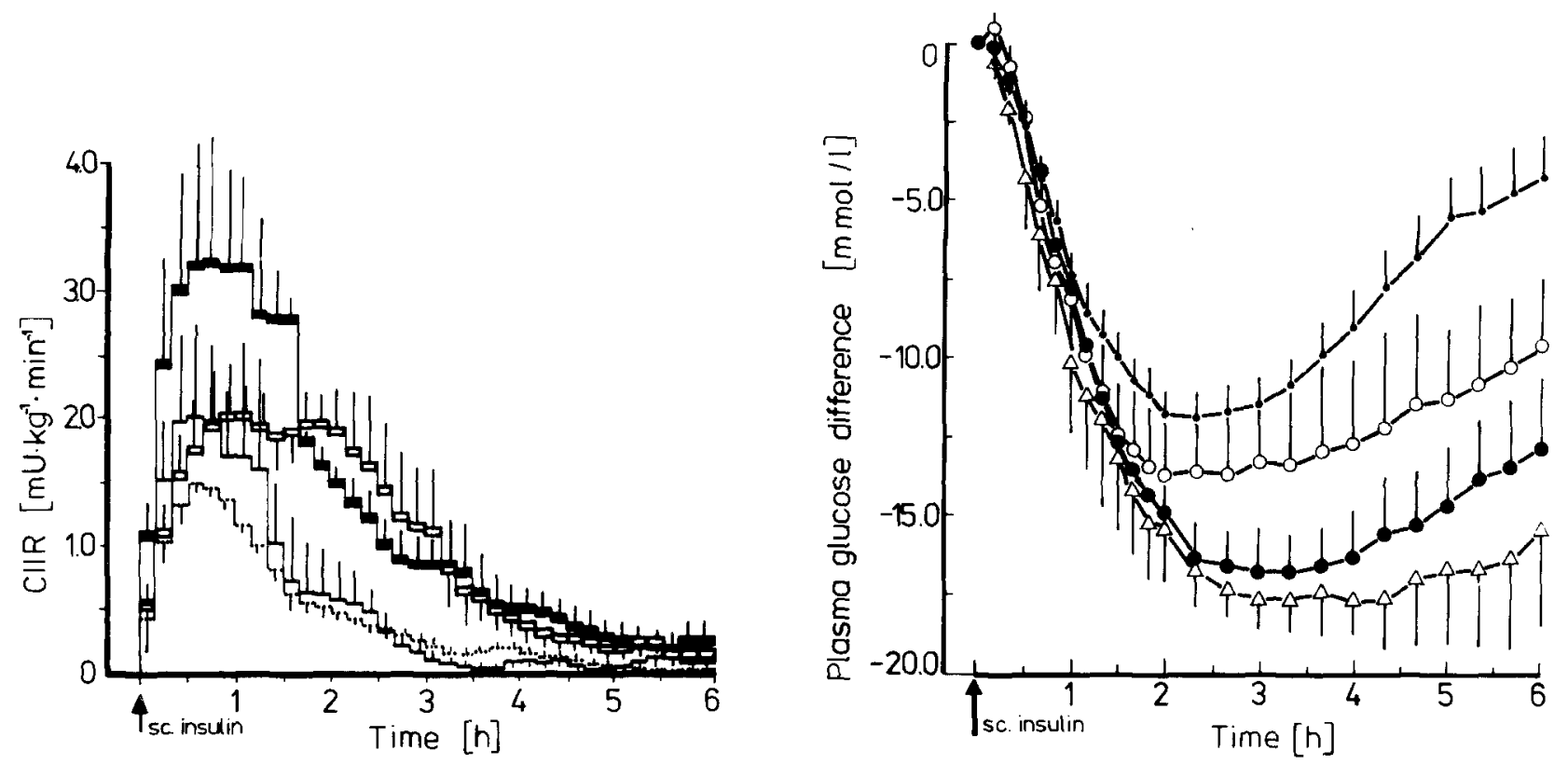

Fig. 1. Subcutaneous injection of highly purified monocomponent porcine insulin (a, see Methods) in fasting diabetic dogs. Observations in five animals which were randomly selected for the individual tests: Left: calculated rates of insulin inflow into the circulating pool (CIIR). Right: decrease in plasma glucose concentration during the same tests. Key $\ldots \ldots=\mathrm{CIIR}$, and $\bullet-=$ glucose decrement for insulin dose $0.16 \mathrm{IU} / \mathrm{kg}$ (nine experiments); $-=\mathrm{CIIR}$, and $\mathrm{o}-\mathrm{o}=$ glucose decrement for insulin dose $0.24 \mathrm{IU} / \mathrm{kg}$ (three experiments), $\square=\mathrm{CIIR}, \bullet-\longrightarrow=$ glucose decrement for insulin dose $0.40 \mathrm{IU} / \mathrm{kg}$ (five experiments), $\boldsymbol{\square}=\mathrm{CIIR}$ and $\triangle \longrightarrow \triangle=$ glucose decrement for insulin dose $0.64 \mathrm{IU} / \mathrm{kg}$ (three experiments). The mean initial plasma glucose levels in the order of increasing doses were $20.92 \pm 1.54,17.37 \pm 3.79,21.82 \pm 1.86$, and 21.81 $\pm 3.05 \mathrm{mmol} / \mathrm{l}$

and $71 \pm 6 \%$ of the applied quantity of insulin and thus appears not to depend on the dose. To test the intra-individual reproducibility one animal was subjected to five tests with $0.16 \mathrm{IU} / \mathrm{kg}$ at weekly intervals. In chronological order the recovery rates were $96,106,76,101$, and $86 \%$. Initial glycaemia in these experiments was $21.9,22.4,27.6,22.6$, and $26.2 \mathrm{mmol} / 1$, and insulinaemia amounted to $0.015,0.000,0.013,0.016$, and $0.037 \mathrm{nmol} / 1$, respectively.

The time-related appearance of soluble insulin in the circulating pool can be described by a double exponential function [23]:

$\mathrm{y}=\mathrm{A} \cdot \mathrm{e}^{\alpha \mathrm{t}}+\mathrm{B} \cdot \mathrm{e}^{\beta \mathrm{t}}+\mathrm{C}$

The parameters of this function were estimated from the least-squares fit of the experimental data, giving estimates of the time $t_{\max }$ of maximum insulin appearance in plasma and the maximum appearance rates $\mathrm{y}_{\max }$ (Table 2).

At the relatively high initial plasma glucose levels observed in this study, the time at which they were affected was not related to the doses or inflow rates of insulin (Fig. 1). The slope of the linear part of the decrease (i.e. $10-60 \mathrm{~min}$ for $0.16 \mathrm{IU} / \mathrm{kg}, 10-70 \mathrm{~min}$ for $0.24 \mathrm{IU} /$ $\mathrm{kg}, 20-90 \mathrm{~min}$ for $0.40 \mathrm{IU} / \mathrm{kg}$, and $10-70 \mathrm{~min}$ for $0.64 \mathrm{IU} / \mathrm{kg}$ ) was $0.15 \mathrm{mmol} \cdot 1^{-1} \cdot \mathrm{min}^{-1}$ for all doses, with correlation coefficients between 0.84 and 0.99 . However, the amount and the duration of the insulin effect were clearly related to the doses and, therefore, to the absorption rates. In contrast to the linear depend-
Table 2. Simulation of the insulin appearance curves after subcutaneous injection of regular insulin by a double exponential function (formula (3))

\begin{tabular}{llll}
$\begin{array}{l}\text { Insulin dose } \\
(\mathrm{U} / \mathrm{kg})\end{array}$ & $\begin{array}{l}\text { Number of } \\
\text { experiments }\end{array}$ & $\begin{array}{l}\mathrm{t}_{\max } \\
(\mathrm{min})\end{array}$ & $\begin{array}{l}\mathrm{y}_{\max } \\
\left(\mathrm{mU} \cdot \mathrm{kg}^{-1} \cdot \mathrm{min}^{-1}\right)\end{array}$ \\
\hline Formulation (a) & & & \\
0.16 & 9 & 34 & 1.48 \\
0.24 & 3 & 34 & 2.11 \\
0.40 & 5 & 68 & 2.10 \\
0.64 & 3 & 40 & 3.35 \\
Formulation (b) & & & \\
0.16 & 2 & 27 & 0.64 \\
0.40 & 2 & 44 & 1.96 \\
\hline
\end{tabular}

Maximum appearance rates $y_{\max }$ and time of maximum $t_{\max }$ as calculated from the fitting parameters. $t_{\max }$ was estimated from the derivative of the double exponential fit according to $t_{\max }=\ln (-\mathrm{A} \alpha / \mathrm{B} \beta) /$ $(\beta-\alpha) . \mathrm{y}_{\max }$ was calculated from equation (3) using the estimated $\mathrm{t}_{\max }$. All correlation coefficients are $\geqslant 0.99$

ence of CIIR on the doses applied, the overall effects of these doses - and therefore of the absorbed amount of insulin as well - showed saturation kinetics (Fig. 2). The glycaemia increased again when the IRI inflow rate fell to $<0.5-0.3 \mathrm{mU} \cdot \mathrm{kg}^{-1} \cdot \mathrm{min}^{-1}$.

The appearance of the depot insulin formulation (c) in the circulation (Fig. 3 ) could also be detected immediately after SC injection, but the rate was lower than that observed for the same dose of soluble insulin. There was a CIIR peak during hour 1 , and insulin inflow into circulation was detectable for $18 \mathrm{~h}$. 


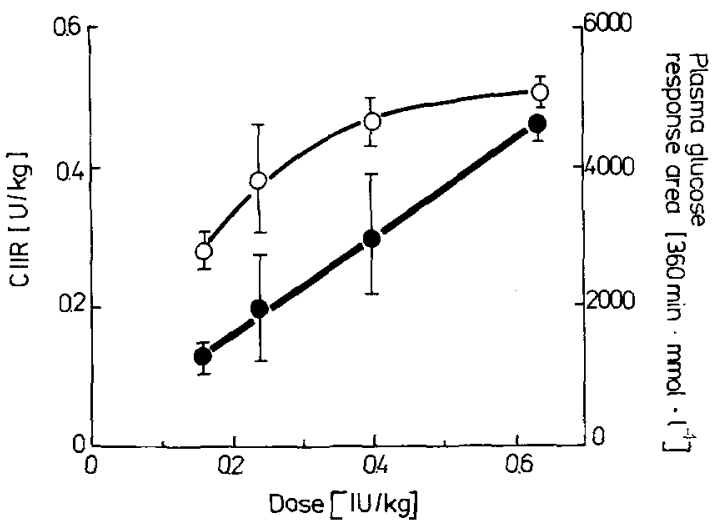

Fig. 2. Relationship of the dose of subcutaneously injected highly purified monocomponent porcine insulin to the amount of insulin appearing in the circulation (CIIR, $\bullet-\bullet$ ) and to the overall glycaemic responses (plasma glucose response area, $0-0$ ). Evaluation of the data from Figure 1

The depot insulin formulation (d) was absorbed even more slowly. The peak was smaller and delayed by 2-4 $\mathrm{h}$. The duration of insulin absorption was, however, also restricted to about $18 \mathrm{~h}$. The recovery of these two depot insulins was $91 \pm 13 \%$ and $80 \pm 11 \%$, respectively. Their effect on the glycaemia was also reflected in the appearance rate which began more slowly after the administration of insulin (d) although the nadir was similar after the injection of both preparations. In the animals examined while still fasting, glycaemia started to increase again after $8-10 \mathrm{~h}$ when CIIR dropped below about $0.3 \mathrm{mU} \cdot \mathrm{kg}^{-1} \cdot \mathrm{min}^{-1}$. It is interesting that in these fasting animals the overall effect was considerably higher than that of the same dose of soluble insulin, but the total dose recovery as CIIR did not differ between these preparations. In this respect the tests in which food was given permit no clear conclusion. It was, however, evident that the absorption of these depot insulins at a rate that was effective in the fasting animal did not prevent post-prandial hyperglycaemia.

Seven comparable pairs of experiments were identified retrospectively so that within the pairs there were considerable differences only in initial blood glucose levels $(25.2 \pm 0.9$ versus $15.6 \pm 0.9 \mathrm{mmol} / 1, \mathrm{p}<0.01)$, with no significant difference between the basal IRI levels $(0.08 \pm 0.03$ versus $0.11 \pm 0.03 \mathrm{mmol} / \mathrm{l})$. Analysis showed that insulin absorption was unaffected by plasma glucose concentration, being $31 \pm 4$ and $29 \pm 7 \%$, respectively, during the first hour and $80 \pm 9$ and $82 \pm 8 \%$ of the total dose. These estimates were based on experiments with the soluble insulin (a).

\section{Discussion}

The model presented gives an approximate estimate of the amount of insulin that enters the peripheral circulation during a given interval. Its applicability requires the following assumptions, which Schlichtkrull [23] has suggested to be probably valid. First, the low endogenous insulin level (if any) must be regarded as constant during the test. Secondly, after absorption into the bloodstream [5] the insulin is assumed to be distributed immediately and uniformly in a single pool which includes the blood plasma. This pool can be determined for the individual with sufficient accuracy (Table 1). Thirdly, insulin is considered to disappear from the pool at a rate characterized by the half-life $\tau$. In the animals in this study all peripheral plasma IRI curves after IV insulin injection clearly showed single-exponential characteristics. This disappearance rate includes insulin

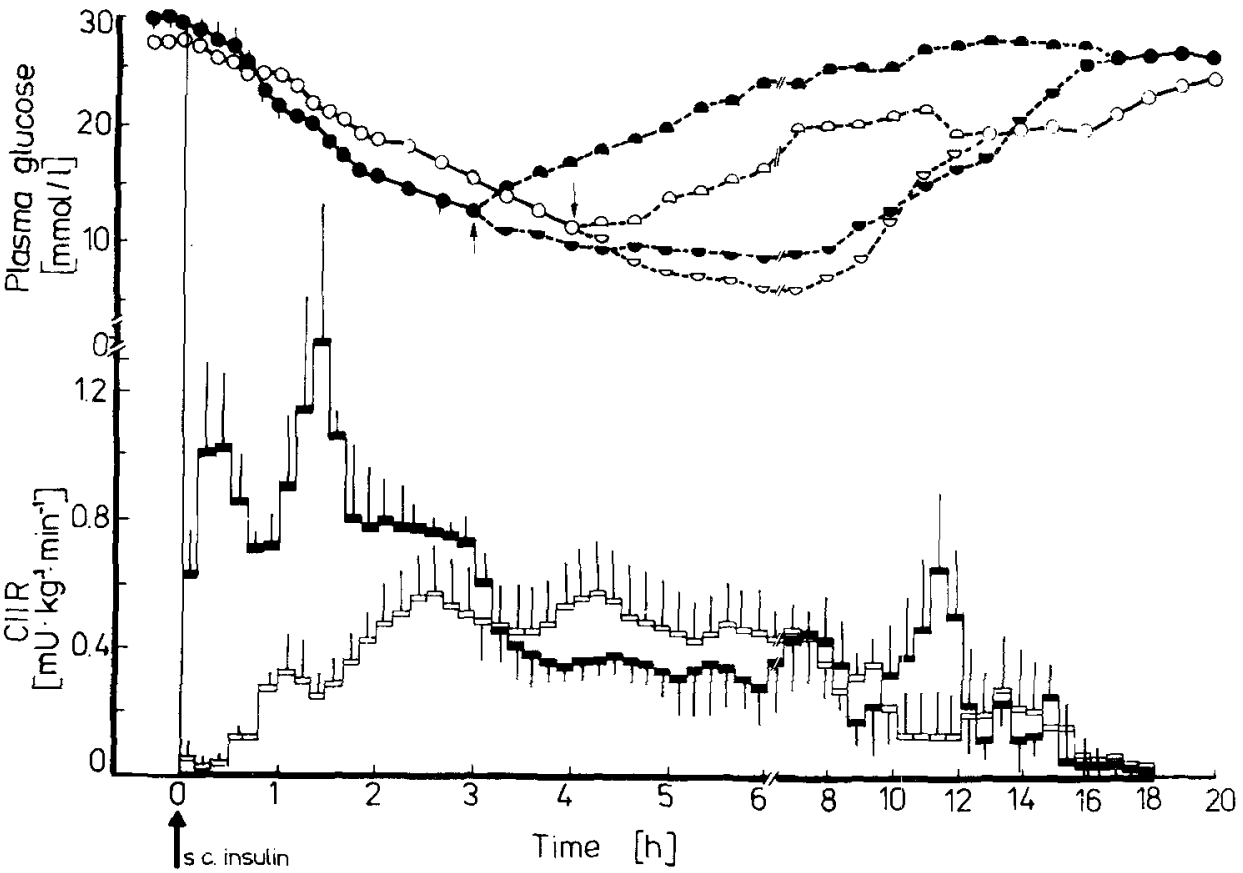

Fig. 3. Plasma glucose concentration (upper panel) and insulin appearance rates CIIR (lower panel) in diabetic dogs after subcutaneous injection of $0.4 \mathrm{IU} / \mathrm{kg}$ depot insulin. The same four animals were studied in each group, two of them receiving an intervenient meal $(\downarrow, \uparrow)$ after 3 or $4 \mathrm{~h}$ respectively. Closed symbols: formulation (c), open symbols: formulation (d) (see Materials and Methods) . O-O = plasma glucose when the values were not different between the fed an the fasted animais; $\triangle O=$ plasma glucose in fed animals, $\triangleright \varnothing_{-1}$ plasma glucose in fasted animals, when results were different after the meals. There was no difference in insulin appearance between the tests with and without meals. SEM is not given when smaller than the symbols or when two experiments or less 
catabolism, receptor binding, and renal excretion. In these experiments the latter can probably be disregarded because it only reaches significant amounts at higher plasma insulin concentrations [11].

The initial validation of the formula showed that it was necessary to introduce a factor for the first pass insulin extraction by the liver [10]. This factor might well vary, but, corresponding to an average loss of $50 \%$ of the insulin reaching the liver via the portal vein $[8,16]$, this factor would be 2.0 for insulin secreted or administered into the splanchnic system. In these experiments, however, $F=1.0$ because the insulin was administered peripherally so that there was no primary (hepatic) drain of the whole dose.

Some knowledge of the amount of insulin actually available in the circulating pool is necessary to improve the current technique of subcutaneous insulin therapy. Individual reproducibility of the results obtained using this model is fairly good; e.g. after injection of soluble insulin $(0.16 \mathrm{U} / \mathrm{kg})$ the coefficient of variation for $t_{\max }$ was $21 \%$ when the animal was studied once a week (unpublished observations). Similar figures were obtained in evaluating dose recovery rates as shown in this study. The inter-individual variation is, however, distinctly greater. Part of the variation in the data presented may result from the use of individually constant values of insulin distribution space and half life. This seems indeed to be justified from the reproducible results in the repeated intra-individual estimations of insulin distribution space and half time (Table 1). It does not, however, consider any effect on IS and $t$ of the maximum insulin concentrations differing between the studies, i. e. subcutaneous administration of different doses or intravenous injection for estimating insulin distribution space and half time. Our observations reveal that soluble insulin appears in the circulating blood at a dose-dependent maximum rate $0.5-1 \mathrm{~h}$ after subcutaneous application and that absorption after $4-6 \mathrm{~h}$ produces no further quantities worth mentioning. According to Schlichtkrull [23], the absorption curve can be fitted to a biexponential function. In the present study it was shown that this approach is useful for describing the characteristics of the insulin preparation and dose concerned.

The magnitude of the initial insulin effect on the glycaemia (around $20 \mathrm{mmol} / \mathrm{l}$ ) is independent of the absorption rate at the doses we investigated, probably because a saturation dose was exceeded. Nevertheless, both the effect on glycaemia and its duration were clear1y related to the dose and absorption rate, as also pointed out by Koivisto and Felig [18] for the post-prandial state. Under these conditions the saturation kinetics in dose effectiveness are clearly not due to any limitations of insulin absorption. This is shown by the linear dose/ CIIR relationship in Figure 2. It seems possible that there is a limit of $0.3-0.5 \mathrm{mU} \cdot \mathrm{kg}^{-1} \cdot \mathrm{min}^{-1}$ below which the effect of insulin on the fasting glycaemia can no longer be discerned. This limit is within the range of the quantity known as the basal insulin dose in automated treatment [9]. Similarly it was shown in diabetic patients that a post-hypoglycaemic increase in glycaemia occurs only when the plasma free insulin levels drop below a certain limit, e.g. $20 \mathrm{mU} / 1$ [12].

Since insulin is continuously metabolized during the interval $\Delta \mathrm{t}$ used for calculation, the formula (1) would slightly underestimate the amount of insulin that really appears in the circulating pool. It has been corrected for this systematic error by using the modified formula (2) of the original model. Since there are intervals both with continuously increasing or decreasing plasma IRI levels during one experiment, no significant error from integration needs to be considered. Thus the dose recovery from these experiments gives an estimate of the loss of insulin at the subcutaneous injection site. Berger et al. $[2,3]$ and Stevenson et al. [26] reported a fractional decomposition of between 10 and $50 \%$ of subcutaneously injected insulin in rats and pigs respectively. Our observation showed a loss of only $0 \%-30 \%$ of the dose given, with considerable variation and with no clear difference between soluble and depot insulins. On the other hand, in a limited study we found a lowered CIIR recovery after subcutaneous injection when a depot preparation (d) was given together with soluble insulin (b) in one syringe in relation to a two-syringe trial. This lowered recovery rate correlated with a reduced action of these doses on glycaemia (unpublished data), showing that there might be a physiologically important degree of insulin catabolism at the subcutaneous injection site. Home et al. [15] observed in brittle diabetic patients both more reproducible and higher plasma insulin concentrations after intramuscular than after subcutaneous insulin administration. They ascribed this difference to varying subcutaneous insulin catabolism and therefore recommended that the intramuscular route be chosen for continuous infusion in treating labile insulindependent diabetic patients.

The present studies provide a possible means of characterizing commercial insulin preparations quantitatively for subcutaneous therapy. The method can also be applied in man [7] if there is no endogenous B cell function and no anti-insulin antibodies, but individual differences $[5,20]$ as well as additional factors influencing the action of the insulin actually available [13, 27] must be taken into account. Problems of reproducibility with particular respect to the action of the insulin applied on post-prandial glycaemia still remain to be investigated.

Acknowledgements. The investigations were made possible by the research project HFR 22 of the Ministry of Health of the GDR. The skillful technical assistance of Mrs. K. Brüllke, Mrs. H. Schröder, Mrs. H. Buff, and Miss K. Köhler is gratefully acknowledged.

\section{References}

1. Asplin CM, Hartog M, Goldie DJ, Smythe P, Alberti KGMM (1980) The role of insulin absorption and sensitivity in determining a diabetics daily insulin dosage. Acta Endocrinol 93: 190-195 
2. Berger M, Halban PA, Assal JP, Offord RE, Vranic M, Renold AE (1979) Pharmacokinetics of subcutaneously injected tritiated insulin: effects of exercise. Diabetes 28: 53-57

3. Berger M, Halban PA, Girardier L, Seydoux J, Offord RE, Renold AE (1979) Absorption kinetics of subcutaneously injected insulin. Evidence for degradation at the injection site. Diabetologia 17: 97-99

4. Berger M, Halban PA, Muller WA, Offord RE, Renold AE, Vranic M (1978) Mobilization of subcutaneously injected tritiated insulin in rats: Effects of muscular exercise. Diabetologia 15: 133-140

5. Binder C (1969) Absorption of injected insulin: a clinical-pharmacological study. Munksgaard, Copenhagen

6. Deckert T (1980) Intermediate-acting insulin preparations: NPH and Lente. Diabetes Care 3: 623-626

7. Fischer U, Freyse EJ, Jutzi E, Höfer S, Bruns W, Keilacker H, Raschke M (1981) The dose-dependent release rate of insulin from subcutaneous deposits of different insulin preparations: investigations on dogs and first results in man. In: Irsigler $\mathrm{K}$, Kunz KM, Owens DR, Regal H (eds) New approaches to insulin therapy. MTP Press, Lancaster, pp 129 136.

8. Fischer U, Hommel H, Gottschling HD, Heinke P, Jutzi E (1975) Estimation of pancreatic IRI output rate and its relation to glucose tolerance in normal anaesthetized dogs. Diabetologia 11: 291-299

9. Fischer U, Jutzi E, Bombor H, Freyse EJ, Salzsieder E, Albrecht G, Besch W, Bruns W (1980) Assessment of an algorithm for the artificial B cell using the normal insulin-glucose relationship in diabetic dogs and men. Diabetologia 18:97-107

10. Fischer U, Jutzi E, Freyse EJ, Salzsieder E (1978) Derivation and experimental proof of a new algorithm for the artificial B cell based on the individual analysis of the physiological insulinglucose relationship Endokrinologie 71: 65-75

11. Franckson JRM, Ooms HA, Arnould Y (1972) The role of the filtration process in the renal catabolism of labelled insulin. Rev Europ Etudes clin biol 17:965-969

12. Gale EAM, Kurtz AB, Tattersall RB (1980) In search of the Somogyi effect. Lancet 2: 279-282

13. Galloway JA (1980) Insulin treatment for the early 80 s: facts and questions about old and new insulins ad their usage. Diabetes Care 3: 615-622

14. Gottschling HD, Ziegler M, Wilke W, Michael R (1974) Radioimmunoassay von Plasmainsulin - methodenkritische Untersuchungen. Radiobiol Radiother 15: 91-97

15. Home PD, Massi-Benedetti M, Shepherd GAA, Alberti KGMM (1980) Twenty-four hour plasma free insulin profiles in 'brittle' diabetics treated by continuous intramuscular and subcutaneous insulin infusion. Diabetologia 19: 284 (Abstract)
16. Jaspan JB, Polonsky KS, Lewis M, Pensler J, Pugh W, Moossa AR, Rubenstein AH (1981) Hepatic metabolism of glucagon in the dog: contribution of the liver to overall metabolic disposal of glucagon. Amer J Physiol 240: E233-E244

17. Koivisto VA, Felig P (1978) Effects of leg exercise on insulin absorption in diabetic patients. New Eng J Med 298: 77-83

18. Koivisto VA, Felig P (1980) Alterations in insulin absorption and blood glucose control associated with varying insulin injection sites in diabetic patients. Ann Int Med 92: 59-61

19. Lambert AE, Buysschaert M, Lambotte L (1979) Use of an artificial pancreas as a tool to determine subcutaneous insulin doses in juvenile diabetes. Diabetes Care 2: 256-264

20. Lauritzen T, Faber OK, Binder C (1979) Variation in ${ }^{125} \mathrm{I}$ insulin absorption and blood glucose concentration. Diabetologia 17: 291-295

21. Neubauer M, Althoff PH, Schnabel O, Genrich V, Schöffling K (1979) Wirkcharakteristik eines biphasischen MonocomponentInsulins. Untersuchungen mit Hilfe der kontinuierlichen automatisierten Blutzuckerregistrierung über 24 Stunden. Dtsch med Wschr 104: 384-390

22. Pickup JC, Keen H, Viberti GC, White MC, Kohner EM, Parsons JA, Alberti KGMM (1980) Continuous subcutaneous insulin infusion in the treatment of diabetes mellitus. Diabetes Care 3: 290-300

23. Schlichtkrull J (1977) The absorption of insulin. Acta Paediatr Scand (Suppl) 270: 97-102

24. Sherwin RS, Tamborlane WV, Genel M, Felig P (1980) Treatment of juvenile-onset diabetes by subcutaneous infusion of insulin with a portable pump. Diabetes Care 3: 301-308

25. Slama G, Buu KN, Tchobroutsky G, Delage A, Desplanque N (1979) Plasma insulin and C-peptide levels during continuous subcutaneous insulin infusion. Diabetes Care 2: 251-255

26. Stevenson RW, Tsakok TJ, Parsons JA (1978) Partial inactivation of insulin injected or infused subcutaneously to rats. Diabetologia 14: 272 (Abstract)

27. Vranic M, Kawamori R (1979) Essential roles of insulin and glucagon in regulating glucose fluxes during exercise in dogs. Mechanism of hypoglycemia. Diabetes $28: 45-52$

Received: 6 January 1982

and in revised form: 17 November 1982

Dr. Uwe Fischer

Central Institute of Diabetes 'Gerhardt Katsch'

DDR-2201 Karlsburg, GDR. 